\title{
Study of Interleukin-1ß in Essential Hypertension
}

\author{
Hoda A. Hassan ,Amal Ahmed Mokhar,Adila M.Gad, Amal Abdel Aleem* \\ Department of General Medicine \& Clinical Pathology* \\ Al Azhar University (Girls)
}

\begin{abstract}
The observation of increased blood interleukin 13 levels in subjects with hypertension is a finding that raises the hypothesis that the immune mechanisms may be involved in the atherogenic cascade. Our aim in this study was to investigate the possible interrelations between blood pressure, lipid profile and IL-1ß to clarify the possible participation of this cytokine in the cascade phenomena presented during the process of essential hypertension (EH) such as atherogenesis.

28 hypertensive patients and 10 healthy volunteers served as control matched for age and sex were included. IL-1ß (enzyme immunoassay), total cholesterol, triglycerides, high and low density lipoprotein cholesterol were estimated. Significant elevation of IL- 13 in hypertensive patients in comparison to the control was found with positive correlation between IL- $1 \beta$ and diastolic. Systolic and the mean Blood pressure $r=0.16,0.046$ and 0.28 respectively. Also the study showed positive correlation between IL-1ß and body mass index ( $\mathrm{r}=0.42)$, serum cholesterol and LDL cholesterol and negative one with TG while no correlation was found with HDL cholesterol TG. Elevated IL-1ß levels in subjects with EH may be related causally to the role of immunologic mechanisms in the development of EH and even to the atherogenic cascade.Thus we can suggest that the presence of high levels of IL-1ß may be an additional risk factor for atherogenesis in patients with $\mathrm{EH}$
\end{abstract}

\section{Introduction}

The dysfunction of the immune system has been implicated recently in the pathogenesis of essential hypertension (EH) (Dalekas et al.,1997), On the other hand alteration in renal handling of salt and water, the rennin angiotensin system, the vascular structure, systemic haemodynamics, the sympathetic activity, environmental or genetic factor, the hyperinsulinaemia and the tissue resistance to insulin have been involved to varying degree in the pathog-enesis of essential hypertension. IL-I forms part of a complete integrated group of cytokines that has been shown to mediate the inflammatory host response to infection Dinarello, $\mathbf{1 9 9 8}$, it has also been implicated in the pathophysiology of endotoxin and immune mediated shock. In vitro evidence suggests that this cytokine may act as a regulatory protein in the atherosclerotic process. Several mechanisms have been suggested including stimulation of leukocyte adherence to the endothelium, modulation of LDL metabolism Rasmuss en \&Seljehid , (1989), induction of extra cellular matrix proteins by endothelium Montensano et al ., (1984) and promotion of vascular permeability Martin et al.,(1989). In 2002 Vito et al observed that nitric oxide and IL- $1 B$ exert a tonic inhibitory action on central sympathetic nervous system activity. IL-1B also suppresses vascular contractility and has procoagulant activity Bevilacqua et al., (1986). In 1989 Wang et al detected increased levels of IL1 and IL- IB m RNAs in human atherosclerotic plaque, however, increasing evidence has accumulated in the last years supporting the speculation that alterations in the function of the immune system could significantly contribute to the cause of many forms of experimental and human essential hypertension. Alteration in both humoral and cellular immunity (khraibi, 1991), inherited abnormalities of the complement system and immunogenetic correlations between histocompatibility antigens with either borderline hypertension have been found (Titkov, et al .,1993). It has recently been shown that antihypertensive 
drugs such as captopril seem to improve the mpaired cellular immune response in patients with EH (Shasha, et al., 1991).

The aim of this work is to study the possible interrelation(s) between IL-B and blood pressure and lipid profile.

\section{Subjects and methods}

Twenty eight hypertensive patients , 18 males and 10 females were admitted to internal medicine department of AL Zahraa hospital for treatment of hypertension or its complications including ischaemic heart disease and hypertensive encephalopathy with one patient was admitted for cerebral haemorrhage with deep coma . their ages ranged between 36 and 71 years (mean $53.07 \pm 10.08$ ) .For all subjects included the following were done: Complete history and thorough clinical examination was done for all subjects to exclude acute inflammatory condition or systemic collagen disease like systemic lupus or rheumatoid arthritis. Electrocardiography and fundus examination was done to detect hypertensive complications . Blood urea and serum creatinine level was done to exclude uraemic patients also fasting blood sugar to exclude diabetic one .Ten healthy volunteers,age and sex matched served as controls.

Blood pressure was measured under a constant conditions at 9 AM. Mean blood pressure (MBP) was assessed by the equation : diastolic $+($ systolic -diastolic)/3, body mass index were calculated by body weight $(\mathrm{Kg})$ / height in (m)2 for every subject. Lipid profile including serum cholesterol (Abell \&Levy,1958) Serum triglycerides(Jacobs \&Van Denmark,1960), low and high density lipoprotein(Finey \&Kostner 1978) were tested. Serum level of Interleukin $-1 \beta$ was measured using ELIZA (enzyme immunoassay).

Statistical analysis

The results were expressed as mean \pm SD. Student $t$ test were used for comparison of means.P value $<0.05$ was considered to be statistically significant. Linear regression analysis was used to calculate correlation coefficient.

\section{Results}

As regard the lipid profile there was significant increase in cholesterol TG, LDL of the patient group than the control while there was significant decrease in HDL in hypertensive patients in comparison to the control .

As regard the IL-1ß. there was significant increase in IL- $1 \beta$ in hypertensive patients in comparison to the control group. Positive correlation was found between IL-1ß and systolic, diastolic and the mean Blood pressure $(\mathrm{P}<0.05)$ r 0.046 , $0.16 \& 0.43$ respectively .

This study showed positive correlation between. IL-1 $1 \beta$ and body mass index (P 0.05 r 0.042) $(\mathrm{P}<0.05)$

As regard the lipid profile we found positive correlation with serum cholesterol and LDL and negative correlation with TG while no correlation was found with HDL.

(Mean \pm SD) of IL- B, Mean B1.P \& Lipid profile in patient's group and control group.

\begin{tabular}{|c|c|c|}
\hline Item. & Control & Patient \\
\hline IL- IB & 0.00 & $4.12 \pm 7.03$ \\
\hline Mean B1 P & $86.6 \pm 10.1$ & $128 \pm 15.9$ \\
\hline Cholesterol & $148.0 \pm 29.08$ & $185.5 \pm 44.2$ \\
\hline TG & $94.7 \pm 11.3$ & $118 \pm 49.1$ \\
\hline LDL & $95.0 \pm 10.6$ & $128.8 \pm 54.7$ \\
\hline HDL & $45.0 \pm 3.08$ & $42.6 \pm 21.4$ \\
\hline
\end{tabular}

Correlations between IL 1B and other parameters

\begin{tabular}{|c|c|c|}
\hline Parameter & IL-1B (R value) & P value \\
\hline Age & 0.04 & $>0.05$ \\
\hline SBP & 0.46 & $<0.05$ \\
\hline DBP & 0.16 & $<0.05$ \\
\hline Mean B I.P & 0.43 & $<0.05$ \\
\hline Body mass index & 0.042 & $<0.05$ \\
\hline
\end{tabular}


Correlation between IL 1B and lipid profile

\begin{tabular}{|c|c|c|}
\hline Parameter & IL-1及 (R value) & P value \\
\hline Cholesterol & 0.351 & $<0.05$ \\
\hline TG & -0.294 & $<0.05$ \\
\hline LDL & 0.453 & $<0.05$ \\
\hline HDL & 0.175 & $>0.05$ \\
\hline
\end{tabular}

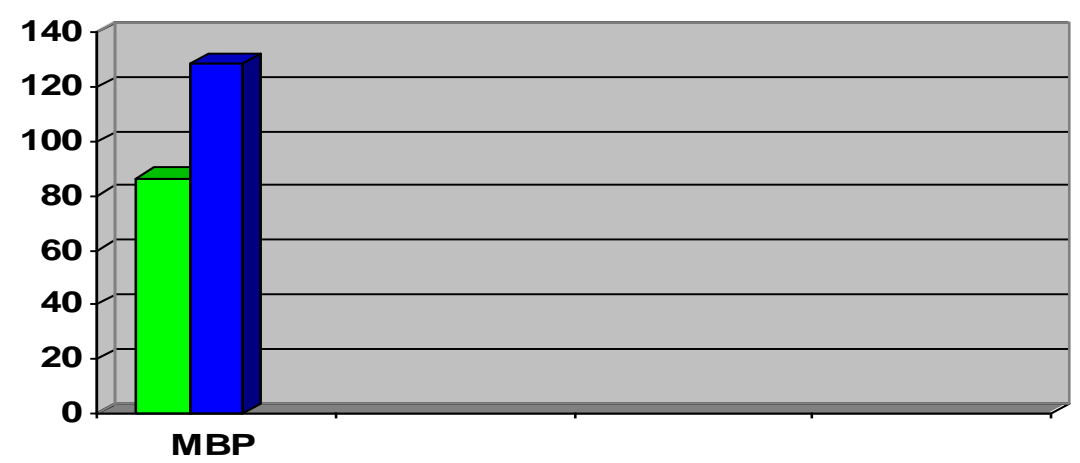

Comparison between MBP among patients and control

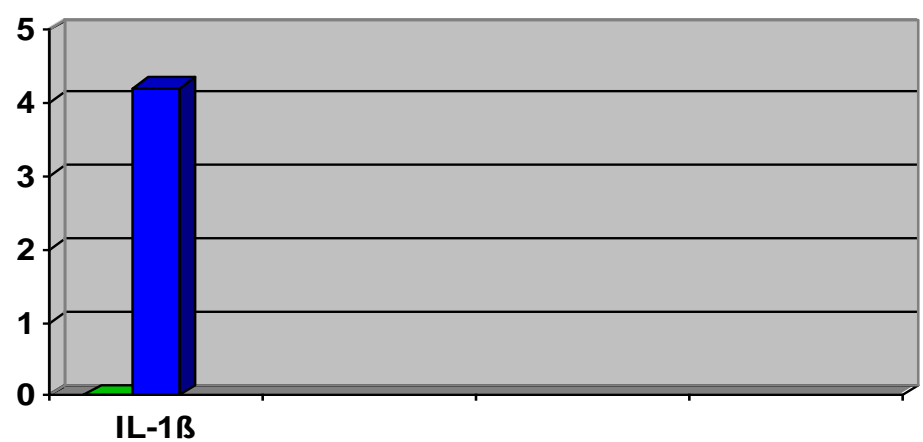

Comparison between IL-1ß among patients and control

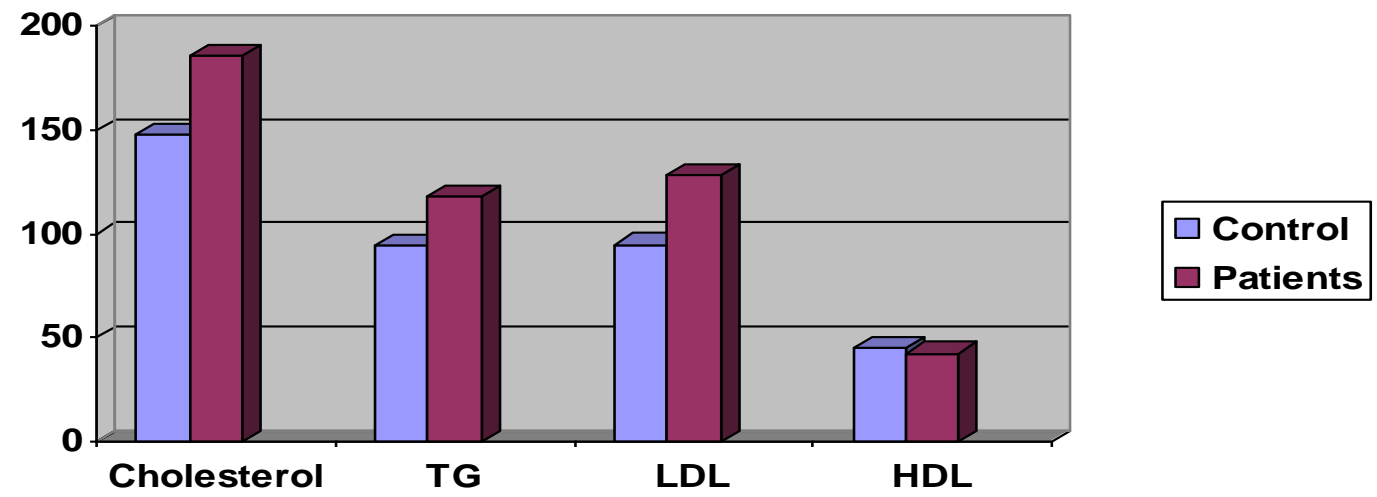

Comparison between lipid profile among control and patients 


\section{Discussion}

Hypertension is commonly associated with the development of atherosclerosis .It has been shown that in hypertension, endothelial dysfunction and subendothelial accumulation of monocytes occur Drffel et al., 1999. Immunopathogenic mechanisms may be involved in the pathogenesis of hypertension . Alterations in both humoral and cellular immunity have been described (Dzielak 1992)

The endothelial cells may be involved in the activation of peripheral blood monocytes. This may be mediated by increased production of TNF- $\alpha$ \& IL-1B in peripheral blood monocyte derived from patients with $\mathrm{EH}$, these cytokines are mediators of inflammatory reactions which have an important role in atherosclerosis Interleukin- 1 is a polypeptide produced by a variety of cells of hematological, dermal and neural origin .

In this study we found significant high levels IL-1ß in systemic circulation of patients with $\mathrm{EH}$ versus the control. In addition, it showed that this increase in IL13 in patients with EH was significantly associated with higher concentrations of total cholesterol and lower concentrations of HDL cholesterol. Contradicting our results, Matsumori et al ., 1994,reported that IL-1ß was not high among patients with hypertension,meanwhile, Drffet et al.,1999 agreed with our results, who found elevated levels of IL-1B in hypertensive patients, they suspect an abnormal inflammatory response associated with the hypertensive disease. Bevilacqua et al 1986 found that IL-1B induce procoagulant activity in cultured human vascular endothelium. Also in 1997 Dalekas., investigated 114 patients with $\mathrm{EH}$ before any drug therapy and found that about $59.6 \%$ of the patients had increased IL-1B levels in the systemic circulation.

In this study we observed a relationship between the age and IL-1 $1 \beta$ values which corresponds to an increasing risk of atherogenesis with age.

The responsiveness of endothelium to factors such as lipopoly saccharide, IL-1ß, tumor necrosis factor- $\alpha$ and interferon- $\gamma$ that promote monocyte adhesion in $\mathrm{EH}$ has been reported to be enhanced( McCarron et al ., 1994).

Positive correlations was found between total cholesterol, triglycerides and LDL cholesterol and IL-1ß with negahie Correlation with TG, also high levels of IL-1ß were associated with a significant increase in patient weight, body mass index which agree with Galea et al.,1996 who observed that IL-1ß has been increased in obese individuals, however, considerable attention has been focused on the involvement of IL-1ß in the develop-ment of atherosclerotic plaques Rossi,1986 Endothelial cells are a target for IL-1ß, which in turn may stimulate the proliferation of vascular smooth muscle cells, In addition foam cells isolated from arterial plaques of hyercholesterolaemic rabbits contain IL- $1 \beta$ and mRNA of IL- $1 \beta$, whereas the uptake of oxidized LDL cholesterol by peripheral monocytes leads to the production of IL-1ß by these cells (Dalekas et al., 1997) .The endothelium is also modified by IL-1ß to favor coagulation and thrombosis while impairing the fibrinolytic process (Zhang et al.,1993). So we can suggest that IL-1ß may be an additional risk factor for atheromatosis in patients with $\mathrm{EH}$. This can be evidenced by inflammation and fibrosis in atheromatous lesions (Rossi, 1986). A large proportion of cholesterol ends up in macrophages (major cell source of IL-1ß). The pivotal role of the macrophages, which gradually transform into the foam cells, emphasizes the importance of inflammatory mechanisms in atherosclerosis (Dalekas et al.,1997).

In conclusion the presence of high levels of IL-1ß may be considered as an additional and perhaps risk factor for atheromatosis in patients with the $\mathrm{EH}$ and must be taken into consideration

\section{Reference}

1. Abell ,J .\& Levy,C.(1958): Determination of serum cholesterol using libermannBurchard reagent. Clin Chem.3,11:221

2. Bevilacqua MP, Pober JS, Majecu GR (1986). Recombinant tumor necrosis factor induced procoagulant activity in cultured human vascular endothelium: 
characterization and comparison with the actions of interleukin 1. Immunology: 83: 4533-4537.

3. Dalekas GN, (1996) elevated interleukin-1 in the circulation of patients with EH before any drug therapy; a pilot study. EM J Clin. Investing . 1996; 26:936-9.

4. Dalekas GN, Elisof M , Tsolas O.(1997) :Increased serum levels of interleukin - 1 in the systemic circulation of patients with $\mathrm{EH}$ .J lab Clin Med. 129; 300-8.

5. Dinarello CA. (1998). The role of IL-1 in disease N Engl J Med 38-13

6. Drffel, Y , Ltsch, CH., Stuhlmver B (1999): Preactivated peripheral blood monocytes in patients with EH. Hypertension, 34: 113-117.

7. Dzielak DJ (1992): The immune system \& hypertension . Hyper., 19, : 36-44

8. Finley,p. \&Kostner,G. (1978): Determination of HDL by colurmetric enzyme method. Clin chem..24,3:931.

9. Galea J, Armstrong $\mathbf{J}$ \&Gadsdon $P$ (1996): IL-1ß in coronary arteries of patients with ischaemic heart disease. Arteriosclerosis, Thrombosis \&Vascular biology, 16: 1000-1006.

10. Jacobs,N. \& Van Denmark,P.(1960): Determination of triglycerides using colourmetric enzyme test. Arch. Biochem. Biophys.88,250-55

11. Khraibi A. (1991): :Association between disturbances in the immune system and hypertension. Am J hypertension; 4: 635-41.

12. Martin S, Murater K, Kolb H (1989): Interleukin -1 and IFN- gamma increase vascular permeability. Immunology. : 64: 301-305.

13. Matsumori A, Yawada $T$ and Sasaywmas., (1994): Increased circulating cytokines in patients with myocardial infarction and cardiomyopathy. Bri Heart J : $72(6)$ : 561-566.
14. McCarron R, Doron D, Siren A and Polland H, (1994) Agonist- stimulated release of von willebrand factor and procoagulant factor VIII without risk factor for stroke Brain Res ;647(2): 265-272.

15. Montensano R, Mossaz A, Ryser J- E, Orci L (1984). leukocyte interleukins induce cultured endothelial cells to produce a highly organized, glycosaminoglycan rich pericellular matrix. J cell B 10 ;99:17061715.

16. Rasmussen L, Seljehid R. (1989) the modulatry effects of lipoprotein on the release of interleukin-1 by human peritonial mocoplages stimulated by WF-13 D polyglucose derivatives. Scand J Immun : 29: 477-484.

17. Rossi R. The pathogenesis of atherosclerosis (1986) : an update. NE J med: 314 : 488.

18. Shasha S., Nusam D., Lebin L (1991). Effect of converting enzyme inhibitor captopril on $\mathrm{T}$ cell functions in $\mathrm{EH}$ Nephron :59:586-90..

19. Titkov Y., Ziakina R., Temirov A(1993): HLA antigens in borderline EH. Am J Hypertension ; 6: 885

20. Vito M, Shaohua Ye, Hinquis Zhong (2002) . Downregulation of neuronal nitric oxide synthesis and Interleukin-1 Mediates Agiostensin- Hypertension . 39: 519.

21. Wang A, Doyle M, Mark D (1989), Quantitation of $m$ RNA using the polymerase chain reaction. Immunology; 86: 9717-9721.

22. Watson D. Cholesterol, colorimetric methd. Clin chim Acta. 1960: 5:637.

23. Zhang Y., Cliff W., Scloefl G (1993) ; Immunohistochemical study of intimal microvessels in cronory atherosclerosis Am. J Patho. 143: 164-72. 


\section{دراسة الانترليدكين بيتا فى مرضى ضغط الام المرتفع الاولى}

* د هدى عبد الباسط محمد حسن ، * أمل أحمد مختار ،* عديلة محمود

$$
\text { جاد }
$$

،

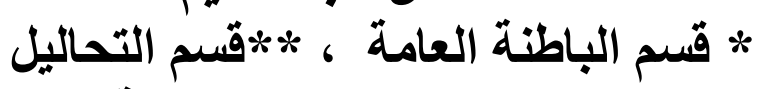

مستثفى الزهر اء الجامعى - جامعة الازهر

أجريت هذه الدراسة على 28 مريض يعانون من ارتفاع فى ضنغط الدم و10

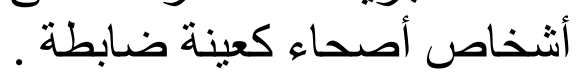

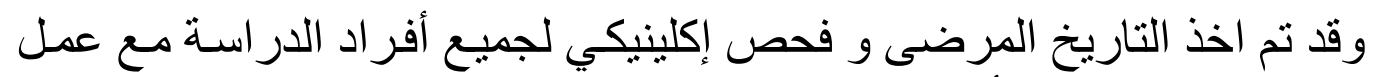

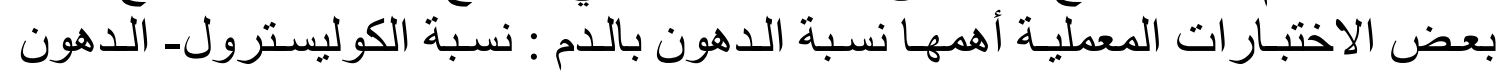

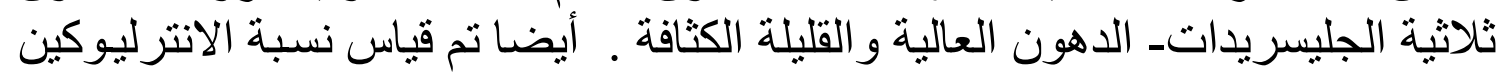

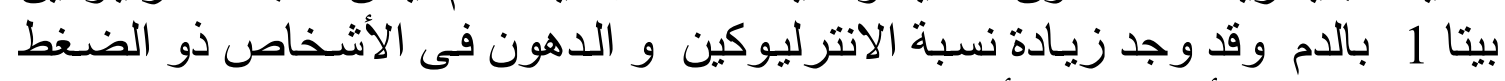

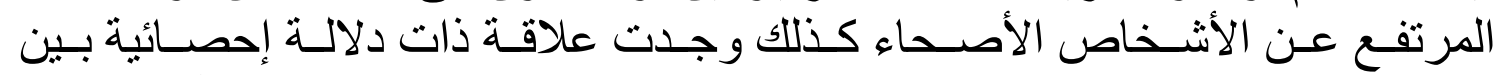

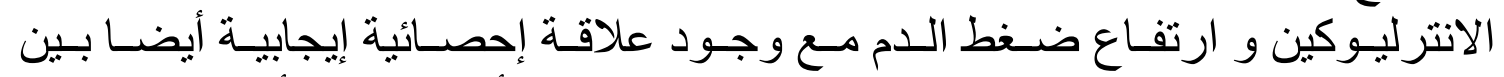

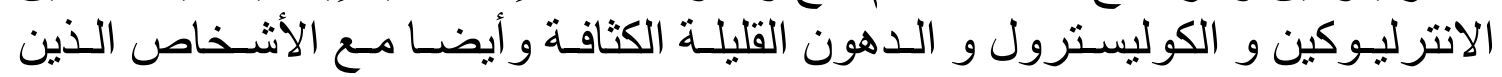

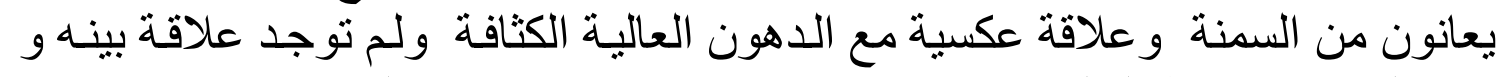

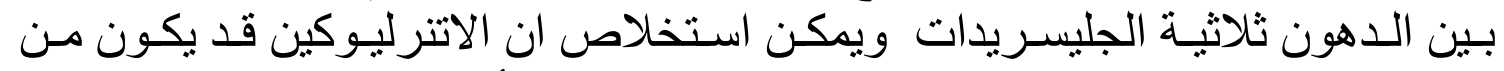

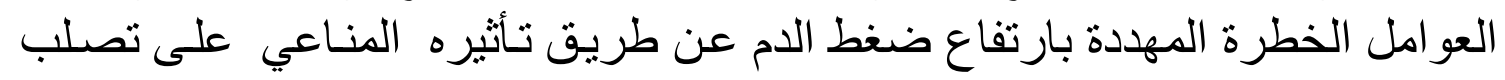
الثر ايين. 